\title{
Idiopathic sclerosing encapsulating peritonitis: an uncommon cause of intestinal obstruction
}

\author{
José de Arimatéia Batista Araújo Filhoa , João Augusto dos Santos Martines ${ }^{\mathrm{b}}$, \\ Brenda Margatho Ramos Martines ${ }^{b}$, Adriano Ferreira da Silva ${ }^{b}$, \\ Silvana Maria Lovisoloc, Cláudio Campi de Castrob,d
}

Araújo Filho JAB, Martines JAS, Martines BMR, Silva AF, Lovisolo SM, Castro CC. Idiopathic sclerosing encapsulating peritonitis: an uncommon cause of intestinal obstruction. Autopsy Case Rep [Internet]. 2012;2(3):51-56. http://dx.doi. org/10.4322/acr.2012.026

\section{ABSTRACT}

Sclerosing encapsulating peritonitis (SEP), also called encapsulating peritonitis, is a rare and benign cause of intestinal obstruction of unknown etiology. Its onset may be acute or subacute although there are some reports with a two-month history. More commonly, this entity is secondary to chronic peritoneal dialysis, ventriculoperitoneal and peritoneovenous shunting, the use of $\beta$-blockers and systemic lupus erythematous. Recurrent episodes of bacterial peritonitis, intestinal tuberculosis, sarcoidosis, familial Mediterranean fever, gastrointestinal cancer, liver transplantation, intra-abdominal fibrogenic foreign bodies, and luteinized ovarian thecomas are also related to SEP. The idiopathic presentation is more rare. Abdominal pain, nausea, vomiting, weight loss, malnutrition, and clinically palpable mass characterize the clinical features. Diagnosis is frequently made with gross findings during surgery, imaging workup and histopathology. The authors report the case of a 36-yearold male patient with a 10-day history of abdominal pain that was operated on because of intestinal obstruction. Diagnosis was made preoperatively and confirmed by the intraoperative findings and histopathology.

Keywords: Abdominal pain; Intestinal obstruction; Peritoneal fibrosis; Surgery.

\section{CASE REPORT}

A 36-year-old male patient sought medical attention complaining of epigastric pain, constipation, and vomiting for about 10 days. He denied past similar episodes, peritoneal dialysis, chronic use of medications, or other comorbidities. On clinical examination, he looked well but the abdomen was distended, diffusely tender on deep palpation, and showed defense and dullness in the left hypochondrium and flank. There were no signs of enlarged viscera, Giordano and rebound signs were negative, and bowel sounds were reduced. Blood cell count on admission showed hemoglobin of $15.6 \mathrm{~g} / \mathrm{dL}$ and leukocytes of $11,700 / \mathrm{mL}(86 \%$ segmented, without shift to the left). Abdominal ultrasound and laboratory workup were unremarkable. Abdominal computed tomography

\footnotetext{
${ }^{a}$ Heart Institute - Hospital das Clínicas - Faculdade de Medicina - Universidade de São Paulo, São Paulo/SP - Brazil.

b Diagnostic Imaging Service - Hospital Universitário - Universidade de São Paulo, São Paulo/SP - Brazil.

${ }^{c}$ Anatomic Pathology Service - Hospital Universitário - Universidade de São Paulo, São Paulo/SP - Brazil.

d Department of Radiology - Faculdade de Medicina - Universidade de São Paulo, São Paulo/SP - Brazil.
} 
(CT) showed conglomerate of the small bowel in the central portion of the abdomen, with some loops exhibiting air-fluid level enclosed by a thick fibrous membrane associated with slight enhancement of the contrast media within the intestinal wall. Slight parietal engorgement of the mesenteric vessels, as well as a small amount of free liquid in the abdominal cavity, were also observed (Figures 1, 2 and 3). The patient underwent an exploratory laparotomy. Surgical findings included segments of the small bowel entrapped by white fibrous tissue forming sacculations, and some inter-loop adhesions without signs of vascular loop suffering. No definite point of obstruction was evident, but free liquid was observed in the abdominal cavity. Partial resection of the fibrous membrane and lysis of the adhesions were undertaken.

The product of surgical excision consisted of multiple irregular fragments of membranous tissue measuring $10.0 \times 8.0 \times 4.0 \mathrm{~cm}$. Histological findings

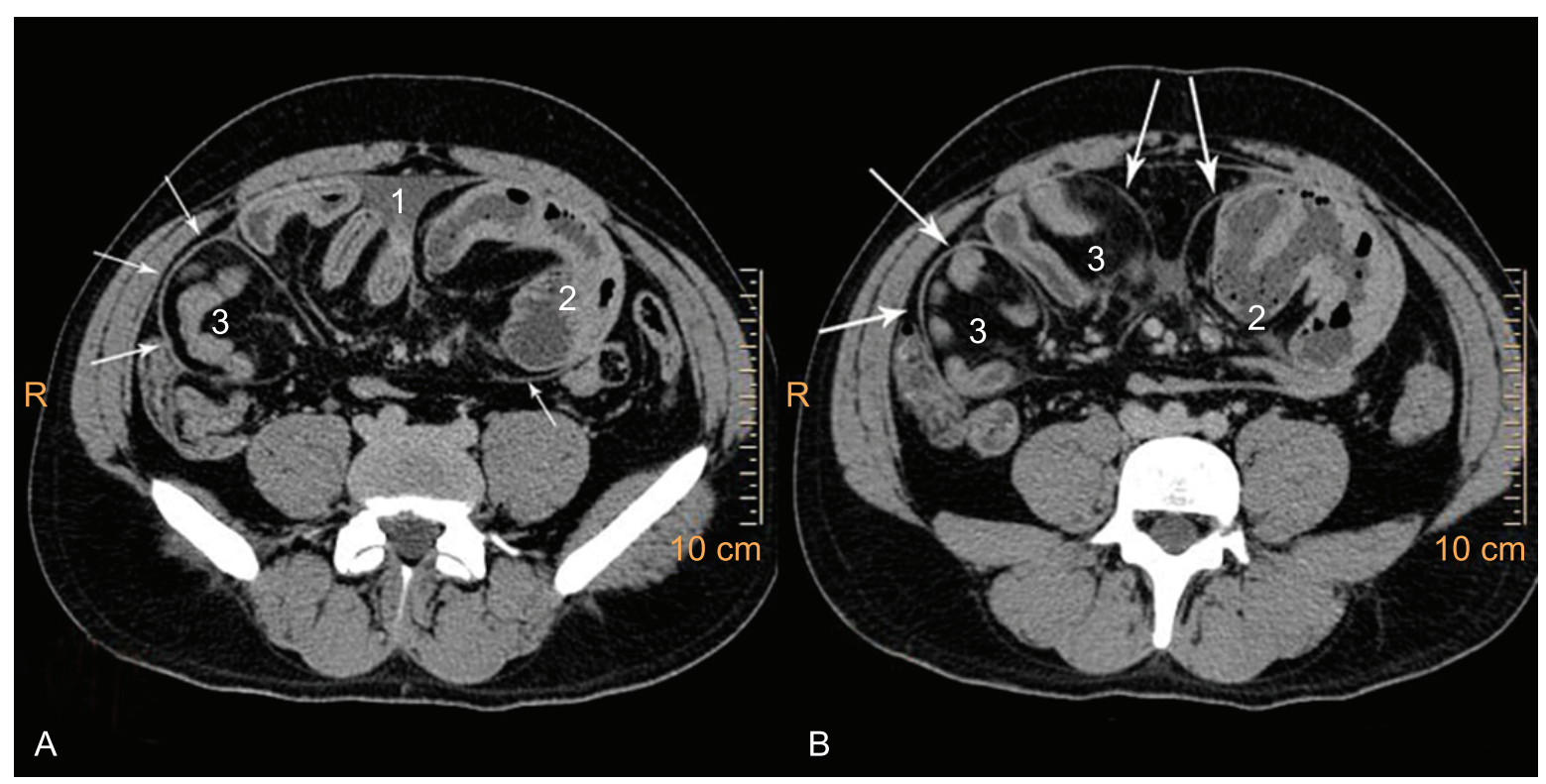

Figure 1 - A and B - Axial computed tomography of the abdomen showing peritoneal thickening (arrows) encasing small bowel segments. Note thickening of the small intestine wall and the presence of free liquid (1) in the abdominal cavity. Dilated jejunal segments can be seen at (2). Ileal segments can be seen at (3), with the former before the intestinal obstruction and the latter after it.

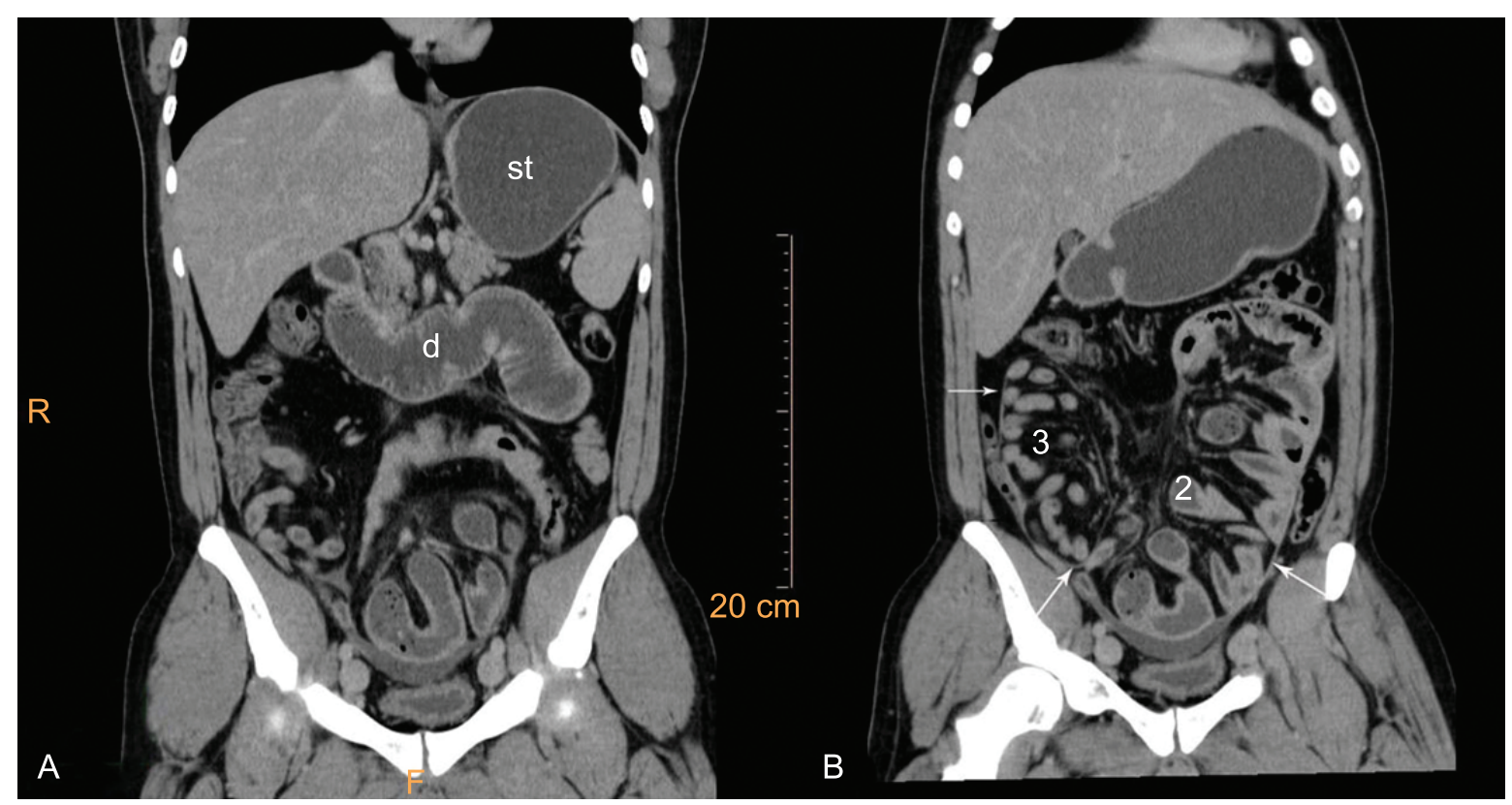

Figure 2 - Computed tomography of the abdomen - coronal plane. A - Dilated stomach (st) and duodenum (d), peritoneal thickening (arrows) and encased small bowel segments in the pelvis; B - Dilated stomach, encased jejunal (2) and ileal (3) segments. 
showed that this membrane mainly consisted of a thin capsular fibrous tissue containing scattered fibroblasts (Figure 4A and $5 \mathrm{~A}$ ) with a deposition of fibrin on the peritoneal surface (Figure 4B and 5B). The thicker areas showed enlarged peritoneal fibroblasts containing large nuclei and increased cellularity distributed throughout the fibrous tissue. This suggested activation of a reactive proliferative state (Figure $6 \mathrm{~A}$ ), resulting in peritoneal collagenation and fibrosis (Figures $5 \mathrm{~A}$

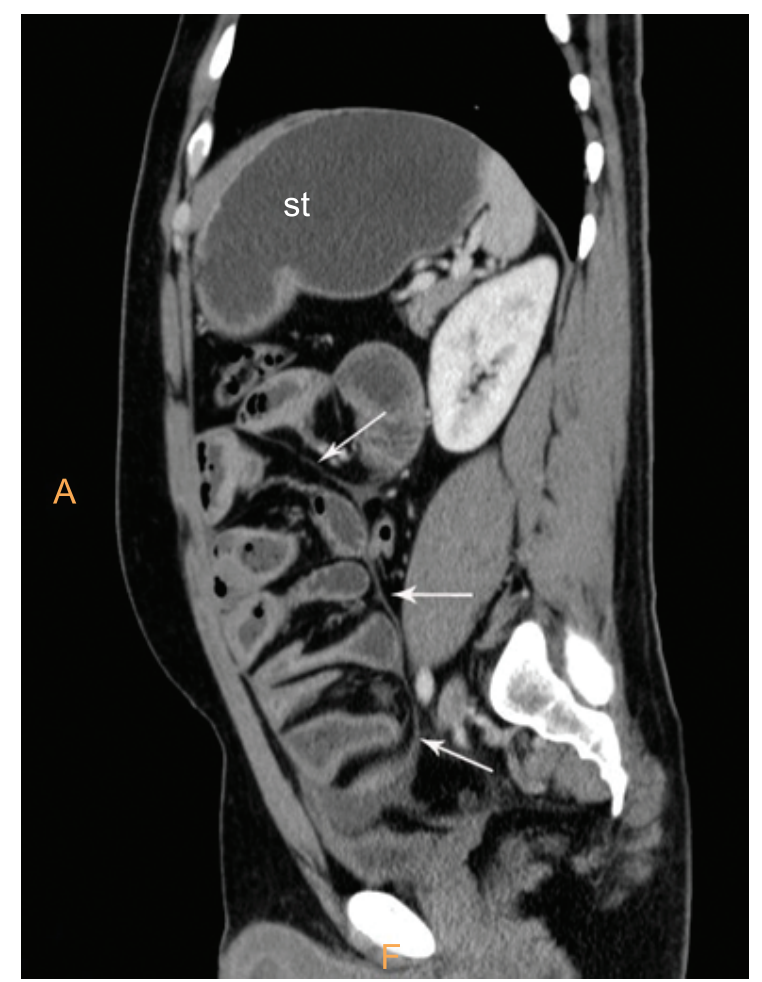

Figure 3 - Computed tomography of the abdomen - sagittal plane. Note dilated stomach (st), thick peritoneum encasing small bowel segments, and free liquid in the peritoneal cavity. and 5B). Capillary angiogenesis (Figure 6A), lymphomononuclear inflammatory cell infiltration (Figures 4B, 5A, and 6B) and perivascular bleeding (Figures 5B and 6B) were also observed. These histopathological findings are characteristic of sclerosing encapsulating peritonitis (SEP).

The outcome was favorable allowing the patient to be discharged on the third postoperative day. The three-month follow up was uneventful.

\section{DISCUSSION}

SEP or sclerosing encapsulating peritonitis, which is also called encapsulating peritoneal sclerosis, encapsulating peritonitis, sclerosing peritonitis, or abdominal cocoon is a rare, benign, acute, or subacute cause of intestinal obstruction, characterized by the entrapment of part of or the entire small intestine by a fibrocollagenous membrane. It was first observed by Owtschinnikow in 1907 and was called "peritonitis fibrosa incapsulata."1-3 Some authors advocate the designation "encapsulating peritoneal sclerosis" for accurately describing this entity once inflammatory features are not necessarily apparent in advanced cases. ${ }^{4}$ Morphologically, a thick white fibrocollagenous membrane adheres to the intestine wall. This membrane is a result of fibroconnective tissue proliferation. The mesothelium is attenuated or focally absent, and occasionally a nonspecific chronic inflammation of varying activity is present. The small intestine is primarily affected, but the colon, liver, stomach, and duodenum may also be involved. ${ }^{5,6}$

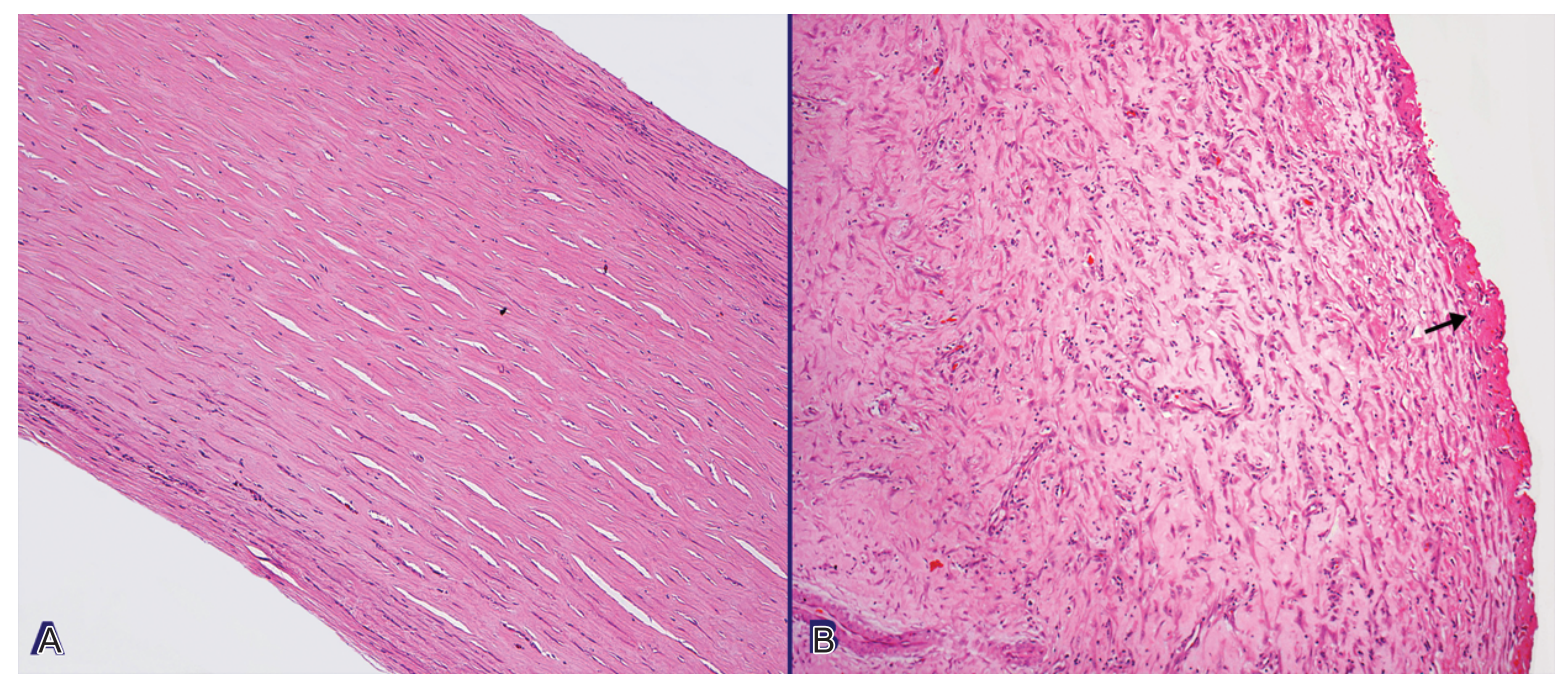

Figure 4 - Photomicrography of the excised fibrous membrane (H\&E stain, 100x). A - Thin lamellar fibrous membrane containing scattered fibroblasts; B - Fibrin deposition on the peritoneal surface (arrow), inflammatory linfomononuclear cell infiltration and interstitial fibrosis. 
SEP can be classified as idiopathic or secondary. The latter, which is more common, was described as being related to chronic peritoneal dialysis, ventriculoperitoneal and peritoneovenous shunting, ${ }^{7}$ the use of $\beta$-blockers (especially practolol and propranolol), ${ }^{8}$ and systemic lupus

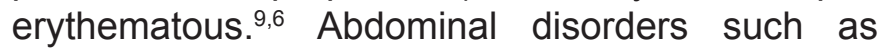
recurrent episodes of bacterial peritonitis, intestinal tuberculosis, sarcoidosis, familial Mediterranean fever, gastrointestinal cancer, liver transplantation, intra-abdominal fibrogenic foreign bodies, and luteinized ovarian thecomas are other potentially associated etiologies. ${ }^{10}$ Initially described in tropical and subtropical adolescent girls, SEP can occur in both genders, all age groups, and several regions of the globe..$^{1,11}$ In the case described here, the patient was a young male with no history or risk factors for developing SEP. Therefore, this case exemplifies an idiopathic variant of this entity, unlike the initial descriptions where the idiopathic type was more common in young females.

Despite some patients being asymptomatic, the most common clinical findings are chronic recurrent episodes of abdominal pain and distension, or abdominal obstruction accompanied by nausea and vomiting, weight loss, malnutrition, and clinically palpable mass. ${ }^{1,12,13}$ In this case study, the clinical presentation was intestinal obstruction that developed over 10 days. The initial sclerosing process may have started earlier and occurred without symptoms. Kinking and compression of the intestines within the constricting membrane

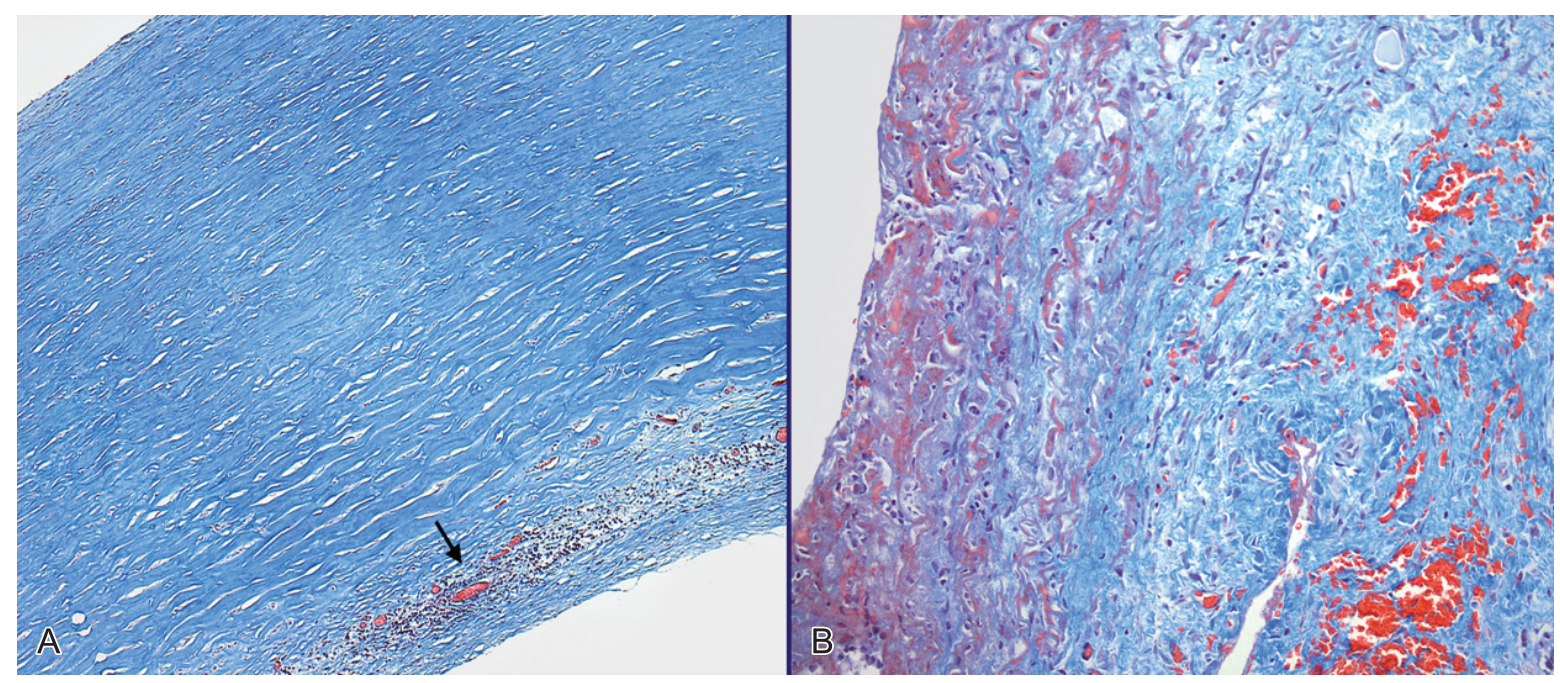

Figure 5 - Photomicrography of the excised fibrous membrane (Masson Trichrome stain, 100x). A - Fibrous membrane (blue) with inflammatory lymphomononuclear cells (arrow); B - Fibrin deposition (dark red), fibrosis (blue) and perivascular bleeding (red cells).

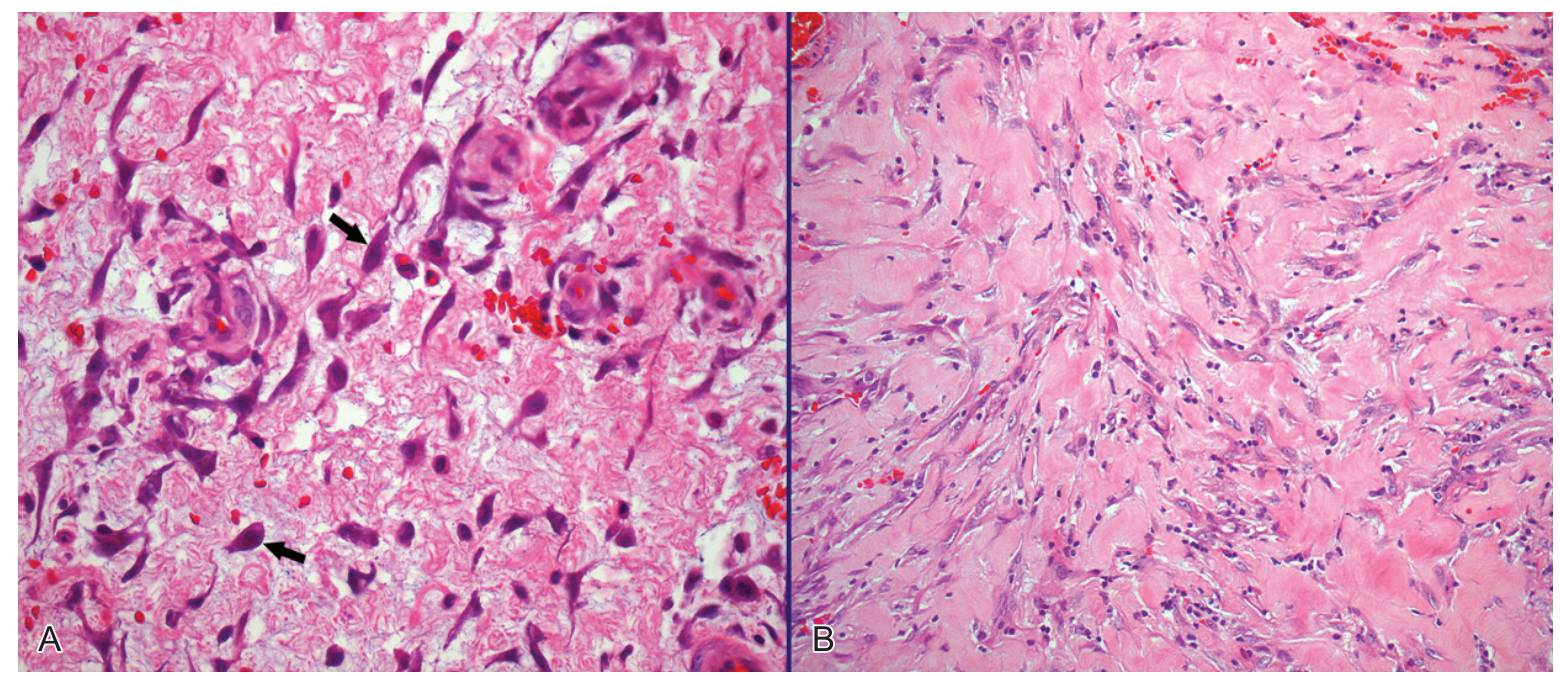

Figure 6 - Photomicrography of the excised fibrous membrane (H\&E stain, 100x). A - Enlarged peritoneal fibroblasts containing large nuclei (arrows) and capillary angiogenesis; B - Reactive fibroblasts, tissue collagenation, inflammatory linfomononuclear cell infiltration and perivascular bleeding. 
represent the physiopathology of the intestinal obstruction. Intestinal obstruction can either be caused by torsion of the bowel or extraluminal compression by a constricting band. ${ }^{6} \mathrm{~A}$ definitive preoperative diagnosis is uncommon; most cases are diagnosed incidentally at laparotomy. A high index of suspicion added to the imaging workup may provide probability to the preoperative diagnosis, which accounts for better treatment and eliminates unnecessary bowel resection. ${ }^{1}$

The radiological diagnostic workup comprises abdominal $\mathrm{x}$-rays showing bowel distension with fluid levels, as in any other cause of bowel obstruction. Contrast studies may reveal a mass of clustered intestinal loops congregated in a single area of the abdomen with delayed or non-progression of the contrast medium. The "cauliflower" appearance described during the bowel transit test shows the small intestine enclosed in a sac. ${ }^{14,15}$ The sonographic features may show the small bowel loops encased in a thick membrane, made visible by minimal ascites. The small bowel loops are shown within the sac, arranged in a concertina shape with a narrow posterior base. ${ }^{16}$ Depending on the clinical context, the findings of dilated bowel loops encased by a thick fibrocollagenous membrane, like a cocoon, in the epigastrium is strongly suggestive of encapsulating peritonitis. ${ }^{10}$ In this case study, the ultrasound examination failed to show the characteristic signs while the CT raised the suspicion preoperatively. CT scans can provide a confident diagnostic approach, furnishing the complete picture of the disease and associated complications excluding other causes of intestinal obstruction. The reported CT findings are: peritoneal and mesenterial thickening; loculated fluid collections or ascites; peritoneal calcification; tethering or matting of the small bowel; marked enhancement of the peritoneum; calcification over liver capsule, spleen, posterior peritoneal wall and bowel; thickening of the bowel wall; and reactive adenopathy. ${ }^{1,2,17}$

Histopathologic diagnosis of encapsulating peritonitis is based on the following criteria: fibrin deposition, fibroblast enlargement, capillary angiogenesis, mononuclear infiltration, and the presence of several immunohistochemical markers for peritoneal fibroblast activation and proliferation. These criteria are not specific but are useful for the diagnosis when combined with surgical or laparoscopic findings. ${ }^{18}$ In this case study, the histopathology of the surgically excised material fulfilled these criteria.
Differential diagnosis includes the causes of small bowel obstruction, particularly adhesions and internal hernias, especially trans-mesenteric and paraduodenal, when differentiation may be challenging. ${ }^{18}$ In this setting, extrinsic masses such as carcinoids, lymphoma, peritoneal carcinomatosis, appendicitis, and diverticulitis should also be considered. Intrinsic causes such as adenocarcinomas, Crohn's disease, tuberculosis, intramural intussusceptions or hemorrhage, radiation enteropathy, intraluminal bezoars, and intestinal malrotation are also considered in the differential diagnosis. ${ }^{10}$

The management of encapsulating peritonitis is still controversial, although some authors advocate the surgical treatment as mandatory aiming the dissection and excision of the interposed membranes with consequent release of the bowel transit. In asymptomatic patients, watchful waiting may be considered. In these cases, corticosteroids, tamoxifen, or other immunosuppressive agents may show some benefits. ${ }^{19}$

In summary, SEP is a rare and challenging preoperative diagnosis, which still has many gaps in its etiology, pathogenesis, diagnosis, and treatment. It should be considered in the diagnosis of recurrent small bowel obstruction associated with radiological findings. Premature recognition of SEP will result in proper management and will prevent unnecessary bowel resection.

\section{REFERENCES}

1. Tannoury JN, Abboud BN. Idiopathic sclerosing encapsulating peritonitis: abdominal cocoon. World J Gasytroenterol. 2012;18:1999-2004. PMid:22563185 PMCid:3342596. http://dx.doi.org/10.3748/wjg.v18.i17.1999

2. Ndiaye AR, Mbengue A, Soko TO, et al. Idiopathic sclerosing encapsulating peritonitis: a case in an adolescent girl. Diagn Intervl Imaging. 2012;93:629-31. PMid:22749202. http:// dx.doi.org/10.1016/j.diii.2012.03.017

3. Honda K, Oda H. Pathology of encapsulating peritoneal sclerosis. Perit Dial Int. 2005;25(suppl 4):s19-29. PMid:16300269.

4. Kawaguchi Y, Kawanishi H, Mujais S, Topley N, Oreopoulos DG. Encapsulating peritoneal sclerosis: definition, etiology, diagnosis, and treatment Ad Hoc Committee on Ultrafiltration management in Peritoneal Dialysis. International Society for Peritoneal Dialysis. Perit Dial Int. 2000;20(Suppl 4):S43-55. PMid:11098928. 
5. Tsunoda T, Mochinaga N, Eto T, Furui J, Tomioka T, Takahara $\mathrm{H}$. Sclerosing encapsulating peritonitis combined with peritoneal encapsulation. Arch Surg. 1993;128:353-5. PMid:8442696. http://dx.doi.org/10.1001/ archsurg.1993.01420150113021

6. Da Luz MM, Barral SM, Barral CM, Bechara Cde S, LacerdaFilho A. Idiopathic encapsulating peritonitis: report of two cases. Surg Today. 2011;41:1644-8. PMid:21969199. http:// dx.doi.org/10.1007/s00595-010-4493-8

7. Sigaroudinia MO, Baillie C, Ahmed S, Mallucci C. Sclerosing encapsulating peritonitis - a rare complication of ventriculoperitoneal shunts. J Pediatr Surg. 2008;43:E31-3. PMid:18485933. http://dx.doi.org/10.1016/j. jpedsurg.2008.01.019

8. Kalra S, Atia A, McKinney J, Borthwick TR, Smalligan $\mathrm{RD}$. Sclerosing encapsulating peritonitis associated with propranolol usage: a case report and review of the literature. J Dig Dis. 2009;4:332-5. PMid:19906115. http://dx.doi. org/10.1111/j.1751-2980.2009.00405.x

9. Pepels MJ, Peters FP, Mebis JJ, Ceelen TL, Hoofwijk AG, Erdkamp FL. Sclerosing peritonitis: an unusual cause of ascites in a patient with systemic lupus erythematosus. Neth J Med. 2006;64:346-9. PMid:17057274.

10. Demir MK, Akinci O, Onur E, Koksal N. Sclerosing encapsulating peritonitis (Case 108). Radiology. 2007;242:9379. PMid:17325076. http://dx.doi.org/10.1148/ radiol. 2423040788

11. Slim R, Tohme C, Yaghi C, Honein K, Sayegh R. Sclerosing encapsulating peritonitis: a diagnoistic dilemma. J Am Coll Surg. 2005;200:974-5. PMid:15922214. http://dx.doi. org/10.1016/j.jamcollsurg.2004.10.038
12. Hamaloglu E, Altun H, Ozdemir A, Ozenc A. The abdominal cocoon: a case report. Dig Surg. 2002;19:422-4. PMid:12435920. http://dx.doi.org/10.1159/000065827

13. Kumar A, Ramakrishnan TS, Sahu S, Mishra KB. Idiopathic sclerosing encapsulating peritonitis - is a preoperative diagnosis possible? Report of 3 cases. Surg Today. 2009;39:610-4. PMid:19562451. http://dx.doi. org/10.1007/s00595-008-3890-8

14. Maguire D, Srinivasan P, O'Grady J, Rela M, Heaton ND. Sclerosing encapsulating peritonitis after orthotopic liver transplantation. Am J Surg. 2001;182:151-4. http://dx.doi. org/10.1016/S0002-9610(01)00685-7

15. Navani S, Shah P, Pandya S, Doctor N. Abdominal cocoon: the cauliflower sign on barium small bowel series. Indian $\mathrm{J}$ Gastroenterol. 1995;14:19. PMid:7860113.

16. Vijayaraghavan SB, Palanivelu C, Sendhilkumar K, Parthasarathi R. Abdominal cocoon: sonographic features. J Ultrasound Med. 2003;22:719-21. PMid:12862272.

17. George C, Al-Zwae K, Nair S, Cast JEl. Computed tomography appearances of sclerosing encapsulating peritonitis. Clin Radiol. 2007;62:732-7. PMid:17604760. http://dx.doi. org/10.1016/j.crad.2007.01.022

18. Blachar A, Federle MP, Dodson SF. Internal hernia: clinical and imaging findings in 17 patients with emphasis on CT criteria. Radiology. 2001;218:68-74. PMid:11152781.

19. Hsu HL, Liu KL, Hung KY. Encapsulating peritoneal sclerosis. Clin Gastroenterol Hepatol. 2010;8:e65. PMid:20144740. http://dx.doi.org/10.1016/j.cgh.2010.01.020

\section{Conflict of interest: None}

Submitted on: $30^{\text {th }}$ June 2012

Accept on: $31^{\text {th }}$ July 2012

Correspondence: Incor - Hospital das Clínicas - Faculdade de Medicina - Universidade de São Paulo Av. Dr. Enéas de Carvalho Aguiar, 44 - São Paulo/SP - Brazil CEP: 05403-000 - Phone: +55 (11) 2661.8110

E-mail: ariaraujocg@hotmail.com 